\title{
Magnetic Mineral Nanocomposite Sorbents for Wastewater Treatment
}

\author{
Oksana Makarchuk, ${ }^{1}$ Tetiana Dontsova, ${ }^{1}$ Anatolii Perekos, ${ }^{2}$ \\ Alexander Skoblik, ${ }^{2}$ and Yevhen Svystunov ${ }^{2}$ \\ ${ }^{1}$ Chemical Technology Department, National Technical University of Ukraine "Igor Sikorsky Kyiv Polytechnic Institute", \\ Victory Avenue 37, Kyiv 03056, Ukraine \\ ${ }^{2}$ G. V. Kurdyumov Institute for Metal Physics National Academy of Sciences of the Ukraine, Academician Vernadsky Blvd. 36, \\ Kyiv 03680, Ukraine \\ Correspondence should be addressed to Oksana Makarchuk; xtfhn9207@ukr.net
}

Received 23 February 2017; Accepted 30 April 2017; Published 29 May 2017

Academic Editor: Vidyadhar Singh

Copyright (C) 2017 Oksana Makarchuk et al. This is an open access article distributed under the Creative Commons Attribution License, which permits unrestricted use, distribution, and reproduction in any medium, provided the original work is properly cited.

Magnetic nanocomposite sorbents for disposal of synthetic detergents from wastewater were synthesized. Obtained sorbents based on clay minerals (saponite, palygorskite, and spondyle clay) and magnetite were characterized by X-ray powder diffraction, Mössbauer spectroscopy, and ballistic method with Steinberg magnetometer. As a result, the average crystallite sizes of $\mathrm{Fe}_{3} \mathrm{O}_{4}$ nanoparticles in magnetic nanocomposites were 2-10 $\mathrm{nm}$. Magnetic nanocomposites had superparamagnetic properties and were classified as soft magnetic materials. Comparison of sorption properties showed that magnetic composite sorbents had efficiency of adsorption removal of anionic surfactants and polyphosphates from aqueous solution 2-8 times higher compared to native clay minerals. Spent magnetic nanocomposites were effectively removed from the aqueous solution by magnetic separation. So, the efficiency of magnetic composites application and implementing of magnetic separation in adsorption purification was confirmed.

\section{Introduction}

Currently there is a shortage, depletion, and quality deterioration of water resources as a result of their growing contamination. Synthetic surfactants (SAs) and polyphosphates have occupied special place among water pollutants. SDs are widely used in household, industry, and agriculture. Although aquatic ecosystems are capable of self-regulation and biological purification, they are unable to cope with the toxic compounds of the SDs that are extremely stable and are stored in the water for years $[1,2]$.

As strong carcinogenic agents SAs and their degradation products are toxic and can accumulate in the body and cause irreversible pathological changes. Furthermore, SAs slow the decay of other carcinogens and inhibit the process of biochemical oxidation and nitrification $[3,4]$.

Soluble phosphorus causes eutrophication of water bodies. Polyphosphates also bring a great harm to the human body; penetrating to skin capillaries they change the percentage of hemoglobin structure and density of the plasma. Besides this, polyphosphate impurities create conditions for more intensive penetration of anionic surfactant through the skin and provoke dermatological diseases [5].

Adsorption purification with a large diversity of sorption materials is a universal method for treatment of both highly concentrated and low concentrated waste water [6]. Activated carbon is the traditional and most commonly used sorbent for water treatment. However, the high cost of activated carbon calls into question the prospects of its use for the treatment of sewage [7].

Cheap clay minerals show a large sorption activity against pollutants of various nature. Mixture of layered and not layered clay minerals is recommended for disposal of wastewater contaminated by SAs [8]. Composite sorbents based clay minerals have high sorption capacity relative polyphosphates [9]. However, the high sorption activity of mineral sorbents 
is provided in the case of colloidal degree of their dispersion. But, in wastewater treatment, a problem of removing of spent sorbent particulate from water occurs.

The solution of this problem is providing magnetic properties for cheap natural clay minerals [10]. As a magnetic modifier magnetic iron oxides $\mathrm{Fe}_{3} \mathrm{O}_{4}, \gamma-\mathrm{Fe}_{2} \mathrm{O}_{3}$, and $\alpha-\mathrm{Fe}_{2} \mathrm{O}_{3}$ are usually used. Magnetic support of sorption treatment of wastewater by cheap natural sorbents, which provides rapid separation of the spent sorbent from purified water in a magnetic field, is beneficial from a technological and economic standpoint [11].

The paper considers the synthesis and characterization of magnetic nanocomposite sorbents based on clay minerals and magnetite; the efficiency of the magnetic composites for wastewater treatment from the anion surfactant and polyphosphates is estimated.

\section{Experimental}

2.1. Synthesis of Composites. Clay minerals, saponite, palygorskite, and spondyle clay (Ukraine) were selected for the creation of the magnetic composites sorbents (MC). These materials have paramagnetic properties. It makes them suitable for creation on their basis of magnetic sorbents. For synthesis of $\mathrm{MC}$, the magnetic modifier $\mathrm{Fe}_{3} \mathrm{O}_{4}$ was used in the form of magnetic fluid obtained by Elmore method [12]. Clay minerals have affinity to multicharged cations (particularly iron ions $\mathrm{Fe}^{2+}$ and $\mathrm{Fe}^{3+}$ ) that determined by morphological, crystal, and chemistry features of clays [13]. Therefore, magnetic composite sorbents based on magnetite in an amount of 7\% wt. and saponite (MCSp-7), palygorskite (MCP-7), and spondyle clay (MCSd-7) were synthesized by simple impregnation method.

2.2. X-Ray Analysis. Powder X-ray diffraction (XRD) analysis of natural clays, magnetite, and composites on their base was performed on Rigaku Ultima IV X-ray powder diffractometer with $\mathrm{Cu} \mathrm{K} \alpha$ radiation $(40 \mathrm{kV}, 30 \mathrm{~mA})$. Crystallographic Open Database (COD) was applied for phase composition definition of sorbents. The crystallite sizes and the unit cell parameters of magnetite and magnetite in magnetic composites were calculated by software package PDXL.

2.3. Mössbauer Spectroscopy. Mössbauer spectra were recorded on MS1101E spectrometer in a mode with constant acceleration employing ${ }^{57} \mathrm{Co}(\mathrm{Cr})$ source. Calibration of isomeric shift $(\delta)$ values was carried out relative to $\alpha$-Fe at room temperature.

2.4. Magnetic Characteristics. Magnetic properties of nanocomposites (specific magnetization $\sigma_{S}\left(\mathrm{~A} \cdot \mathrm{m}^{2} / \mathrm{kg}\right)$; magnetic field strength $H_{c}(\mathrm{~A} / \mathrm{m})$; magnetic induction $\left.B_{r}(\mathrm{mT})\right)$ were determined by ballistic magnetometer of Steinberg.

2.5. Adsorption Procedure. Comparative analysis of $\mathrm{MC}$ sorption properties and natural clays was carried by constructing of adsorption isotherms of main components of synthetic detergents removal such as anionic surfactants (sodium dodecyl benzenesulfonate (SDBS), sodium lauryl sulfate (SLS)) and polyphosphates (tripolyphosphate (TPP) and hexametaphosphate (HMP)). Adsorption properties of magnetite were not studied since $\mathrm{Fe}_{3} \mathrm{O}_{4}$ is a not porous material.

For sorption studies, a series of 250-mL glass flasks were filled with $100 \mathrm{~mL}$ of model wastewater solution of different initial contaminant concentrations $\left(50-1000 \mathrm{mg} \cdot \mathrm{L}^{-1}\right)$. A fixed amount of sorbent material $(1 \mathrm{~g})$ was added to each flask and stirred $(350 \mathrm{rpm})$ for 1 hour at thermostatic water bath shaker $\left(20 \pm 2^{\circ} \mathrm{C}\right)$ to ensure complete sorption equilibrium. After adsorption, spent magnetic composites MCSp-7, MCP7, and MCSd-7 were separated by the external magnetic field, while clays adsorbents saponite, palygorskite, and spondyle clay were separated with centrifugal separation. The residual (equilibrium) concentration of anionic SAs in the sample was measured by direct two-phase (2P) titration of cationic surfactant in the layer of chloroform [14]. The equilibrium concentrations of phosphate in the solutions after adsorption treatment were determined by photometric method of molybdophosphate blue complex using UV-5800PC Spectrophotometer [15]. The equilibrium adsorption capacities $\left(Q_{e}\right)$ were calculated according to the following formula:

$$
Q_{e}=\frac{\left(C_{e}-C_{0}\right) \cdot V}{m},
$$

where $C_{0}$ and $C_{e}$ are initial and equilibrium concentration of pollutant in solution, respectively, $\mathrm{mg} \cdot \mathrm{L}^{-1} ; V$ is model solution volume, $\mathrm{L} ; m$ is mass of sorbent sample, $\mathrm{g}$.

2.6. Magnetic Separation. The magnetic separation process was investigated in an aqueous medium in magnetic filter equipped with permanent magnets with an intensity of external magnetic field $66 \mathrm{mT}$ and in the absence of permanent external magnetic field. The efficiency of magnetic separation was determined by the residual concentration of suspended sorbent particles in aqueous medium through 5, 30, and 60 min of magnetic separation by turbidimetric method [16].

\section{Results and Discussion}

3.1. XRD Analysis. Results of powder X-ray diffractions of magnetite, MC, and natural clays were recorded using a Rigaku Ultima IV diffractometer. The corresponding diffraction patterns are presented in Figure 1 (magnetite), Figure 2 (MCSp-7 and saponite), Figure 3 (MCP-7 and palygorskite), and Figure 4 (MCSd-7 and spondyle clay).

From the XRD pattern of $\mathrm{Fe}_{3} \mathrm{O}_{4}$ (Figure 1), the strong characteristic peaks of $\mathrm{Fe}_{3} \mathrm{O}_{4}$ were detected at $2 \theta(h \mathrm{kl})=$ $30.72^{\circ}$ (220), $35.58^{\circ}$ (311), $43,72^{\circ}$ (400), 53.64 ${ }^{\circ}$ (422), $57.24^{\circ}$ (511), and $62.86^{\circ}$ (440) (card number 01-071-6336). The XRD results do not show the presence of impurities or of other phases. So, the method of Elmore provides obtaining the pure magnetic modifying agent.

The XRD pattern of the native saponite (Figure 2(a)) indicated peaks that correspond to saponite (card number 00-013-0305), montmorillonite (card number 00-002-0014), quartz (card number 00-001-0649), and calcite (card number 


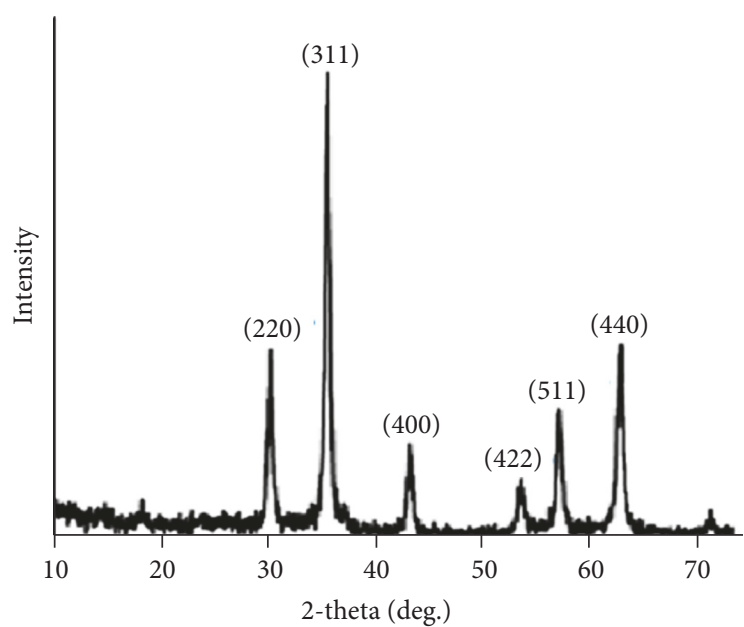

FIgURE 1: The XRD patterns of magnetite $\mathrm{Fe}_{3} \mathrm{O}_{4}$.

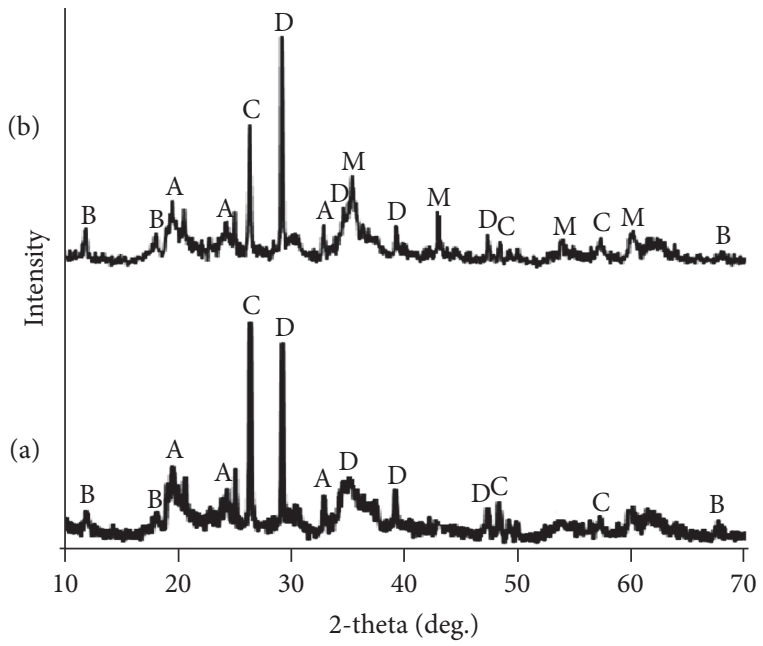

FIGURE 2: The XRD patterns of saponite (a) and MCSp-7 (b): A, saponite $\mathrm{NaMg}_{3}\left[\mathrm{AISi}_{3} \mathrm{O}_{10}\right](\mathrm{OH})_{2} \cdot 4 \mathrm{H}_{2} \mathrm{O} ; \mathrm{B}$, montmorillonite $\mathrm{NaMgAlSiO}_{2}(\mathrm{OH}) \cdot \mathrm{H}_{2} \mathrm{O} ; \mathrm{C}$, quartz $\mathrm{SiO}_{2} ; \mathrm{D}$, calcite $\mathrm{CaCO}_{3} ; \mathrm{M}$, magnetite $\mathrm{Fe}_{3} \mathrm{O}_{4}$.

00-002-0623). The X-ray diffraction pattern of composite sorbent MCSp-7 (Figure 2(b)) showed well-developed diffraction lines assigned to inherent phases of native saponite clay, with all major peaks matching the standard pattern of $\mathrm{Fe}_{3} \mathrm{O}_{4}$ (card number 01-071-6336).

Broad diffraction peaks attributed to peaks of pure palygorskite (card number 01-082-1872) and quartz (card number 00-001-0649) were demonstrated on the XRD pattern of palygorskite (Figure 3(a)). The characteristic diffraction peaks of sets of these two main phases were observed in diffraction pattern of magnetic composite MCP-7 (Figure 3(b)). The position of the rest diffraction peaks of MCP-7 diffraction pattern was well matched with data from the COD card for $\mathrm{Fe}_{3} \mathrm{O}_{4}$.

According to the $\mathrm{X}$-ray diffraction analysis presented in Figure 4, a spondyle clay consists of two minerals such

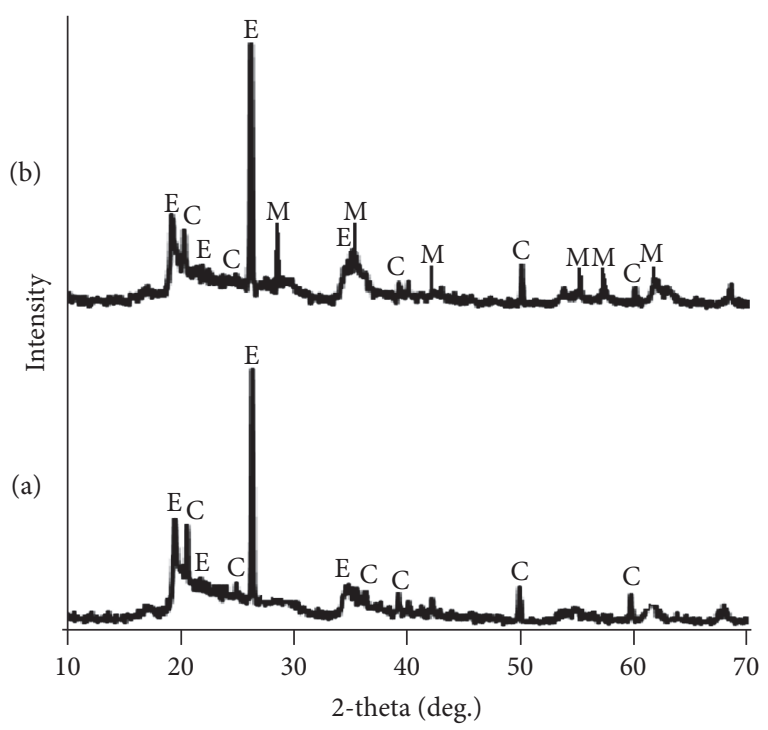

FIGURE 3: The XRD patterns of palygorskite (a) and MCP-7 (b): $\mathrm{E}$, palygorskite $\left(\mathrm{Mg}_{0.669}, \mathrm{AI}_{0.331}\right)_{4}\left(\mathrm{Si}_{4} \mathrm{O}_{10}\right)_{2}(\mathrm{OH})_{2} \cdot 8 \mathrm{H}_{2} \mathrm{O} ; \mathrm{C}$, quartz $\mathrm{SiO}_{2} ; \mathrm{M}$, magnetite $\mathrm{Fe}_{3} \mathrm{O}_{4}$.

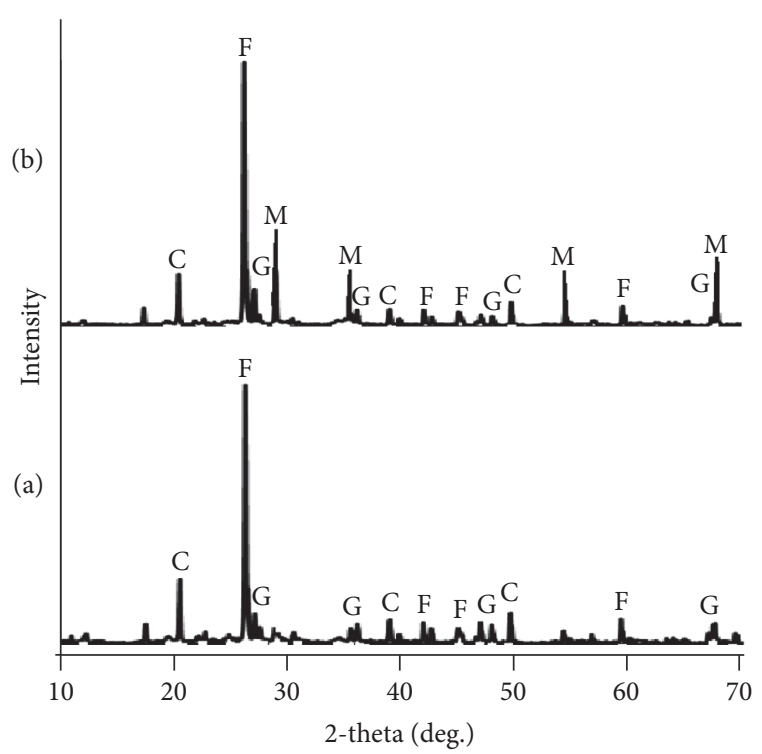

FIgURE 4: The XRD patterns of spondyle clay (a) and MCSd-7 (b): $\mathrm{F}$, augite $\mathrm{Ca}(\mathrm{Mg}, \mathrm{Fe}, \mathrm{Al})\left[(\mathrm{Si}, \mathrm{Al})_{2} \mathrm{O}_{6}\right] ; \mathrm{G}$, pigeonite $(\mathrm{Ca}, \mathrm{Mg}, \mathrm{Fe})(\mathrm{Mg}$, $\mathrm{Fe}) \mathrm{Si}_{2} \mathrm{O}_{6} ; \mathrm{C}$, quartz $\mathrm{SiO}_{2} ; \mathrm{M}$, magnetite $\mathrm{Fe}_{3} \mathrm{O}_{4}$.

as augite (card number 01-088-0831) and pigeonite (card number 01-087-0693). Phase composition of sample MCSd7 differs from native spondyle clays by the presence of magnetite peaks (card number 01-071-6336).

Thus, the synthesis of composite magnetic sorbents impregnation method did not lead to changes in the phase composition of clay minerals.

The XRD patterns of MC and magnetite were automatically analyzed by software package PDXL. The crystallite sizes and the unit cell parameters of magnetite and magnetite in magnetic composites were calculated and reported in Table 1. 
TABLE 1: X-ray analysis of magnetic sorbents on the base of saponite, palygorskite, spondyle clay, and magnetite.

\begin{tabular}{lcccc}
\hline \multirow{2}{*}{ Sample } & Average size of & \multicolumn{3}{c}{ Cell parameters, $\mathrm{nm}$} \\
& $\mathrm{Fe}_{3} \mathrm{O}_{4}$ crystallites, $\mathrm{nm}$ & $\mathrm{a}$ & $b$ & $c$ \\
\hline MCSp-7 & 9.6 & 0.833 & 0.833 & 0.833 \\
$\mathrm{MCP}-7$ & 2.5 & 0.844 & 0.844 & 0.844 \\
$\mathrm{MCSd} 7$ & 9.2 & 0.831 & 0.831 & 0.831 \\
$\mathrm{Fe}_{3} \mathrm{O}_{4}$ & 17.9 & 0.835 & 0.835 & 0.835 \\
\hline
\end{tabular}

As stated in Table 1 magnetite in composite sorbents were obtained in the nanorange. The average crystallite size of $\mathrm{Fe}_{3} \mathrm{O}_{4}$ nanoparticles was $2-10 \mathrm{~nm}$. So, magnetic nanocomposites are received, where nanosized magnetic modifier stabilized in the clay mineral matrix.

3.2. Mössbauer Spectroscopy. Mössbauer spectrums of native saponite clay (Figure 5(a)) and magnetic composite based on its MCSp-7 (Figure 5(b)) were similar to each other. Both spectrums were characterized by the presence of doublets with parameters corresponding to bivalent $\mathrm{Fe}^{2+}$ and trivalent $\mathrm{Fe}^{3+}$ iron ions. Spectrum of saponite included the sextet of low intensity, which showed the presence of magnetite in the composition of native natural clay in small quantities. Sextet of great intensity that according to work [17] corresponds to $\mathrm{Fe}_{3} \mathrm{O}_{4}$ particles with sizes less than $10 \mathrm{~nm}$ [17] was found in the spectrum of MCSp-7.

In the Mössbauer spectrums of MCP-7 (Figure 5(d)) and MCSd-7 (Figure 5(f)) the superposition of two components such as poorly intensive extended sextet that according to work [17] corresponds to $\mathrm{Fe}_{3} \mathrm{O}_{4}$ particles with dimensions less than $10 \mathrm{~nm}$ and doublet that meets parameters of trivalent iron ions $\mathrm{Fe}^{3+}$ occurred. Parameters of doublet shown in Figure 5(d) coincided with doublet of iron ions $\mathrm{Fe}^{3+}$ of the native palygorskite (Figure 5(c)). As shown in Figure 5(e) in the initial state for spondyle clay the existence of two doublets was discovered. In addition to intense doublet parameters which well coincided with doublets for iron ions $\mathrm{Fe}^{3+}$ of MCSd-7 (Figure 5(f)) the doublet of weak intensity with parameters corresponding to bivalent iron ions $\mathrm{Fe}^{2+}$ was detected.

Thus, Mössbauer spectrums of all MC samples except sextets were characterized by presence of doublets. This confirms that the magnetic modifier particles of magnetic composite sorbents are in nanoscale range (less than $10 \mathrm{~nm}$ ) and have superparamagnetic properties [17]. Thereby, the magnetic properties of nanosized magnetite stabilized by mineral matrix are primarily determined by the size of its particles.

3.3. Characteristics of the Magnetic Properties. The specific saturation magnetization, magnetic field strength, and magnetic induction of saponite, palygorskite, spondyle clay, $\mathrm{Fe}_{3} \mathrm{O}_{4}$, and synthesized $\mathrm{MC}$ samples are summarized in Table 2. Natural clays were characterized by specific saturation zero magnetization; therefore these minerals were
TABLE 2: Magnetic characteristics of sorbent samples.

\begin{tabular}{lccc}
\hline Sample & $\sigma_{S(10)}, \mathrm{A} \cdot \mathrm{m}^{2} / \mathrm{kg}$ & $H_{c}, \mathrm{~A} / \mathrm{m}$ & $B_{r}, \mathrm{mT}$ \\
\hline Saponite & 0 & 0 & 0 \\
MCSp-7 & 4.5 & 954.9 & 0.16 \\
Palygorskite & 0 & 0 & 0 \\
MCP-7 & 3.9 & 954.9 & 0.10 \\
Spondyle clay & 0 & 0 & 0 \\
$\mathrm{MCSd} 7$ & 6.3 & 1909.9 & 0.20 \\
$\mathrm{Fe}_{3} \mathrm{O}_{4}$ & 90.0 & 501.3 & 3.50 \\
\hline
\end{tabular}

classified as paramagnetic materials. When paramagnetic mineral matrix of composite enters to the magnetic separator, it is magnetized in the direction of the external magnetic field. Therefore, controllability of magnetic separation process is determined by the properties of ferromagnetic particles of modifier.

In the synthesis of MCSp-7, MCP-7, and MCSd-7 in the clay matrix, the $\mathrm{Fe}_{3} \mathrm{O}_{4}$ crystallites were formed about the same size of 2-10 nm (Table 1); based on this, the specific saturation magnetization of MC samples was approximately the same. Hence, the nanoscale magnetite particles of composite sorbents were formed with the low residual magnetization; therefore MC are classified as soft magnetic materials.

According to the results presented in Table 2, the values of magnetic field strength $\mathrm{Hc}$ and magnetic induction $\mathrm{Br}$ are growing with the increasing of size of $\mathrm{Fe}_{3} \mathrm{O}_{4}$ crystallites. However, for nanosized magnetite with size of crystallites $17.9 \mathrm{~nm}$, the $H c$ value was found relatively low. This regularity is typical for nanoscale particles of magnetic oxides. The maximum value $H c$ is characteristic for magnetite nanoparticles with size of about 30 nanometers. Since the magnetite change of reversal mechanism from reorientation of magnetic moments (single-domain state) to displacement of domain walls (polydomain state) for magnetite particles occurred at about $30 \mathrm{~nm}$ [18], consequently, for single-domain nanoparticles of $\mathrm{Fe}_{3} \mathrm{O}_{4}$ less than $30 \mathrm{~nm}$ is inherent in the increase of magnetic field strength with increasing in size. For magnetite nanoparticles larger than $30 \mathrm{~nm}$ the descending dependency of $H c$ versus particle size was discovered. Thereby, nanoscale particles of magnetic modifier in the composition of magnetic sorbents were characterized by superparamagnetic properties.

3.4. Adsorption Experiment. The maximum sorption capacity of MCSp-7, MCSd-7, and MCP-7 in relation to the anionic SAs was in the range of $35-47 \mathrm{mg} \mathrm{SDBS} / \mathrm{g}$ and $30-36 \mathrm{mg}$ SLS/g (Figures 6(a) and 6(b)). The sorption capacities of native saponite, spondyle clay, and palygorskite for SDBS and SLS obtained from the sorption isotherms were 2-4 and 2-8 times lower. As we can see from Figures 6(c) and $6(\mathrm{~d})$, the maximum sorption capacities of magnetic composites towards TPP and HMP were 3 and 4 times higher, respectively, compared to the native clay minerals and amounted to 550-570 $\mathrm{mg} \mathrm{TPP} / \mathrm{g}$ and $790-810 \mathrm{mg} \mathrm{HMP} / \mathrm{g}$.

Thus, modification of clay minerals using nanoscale magnetite in an amount of 7 wt.\% has enhanced adsorption capacity of natural clays. In our view, it was related to 

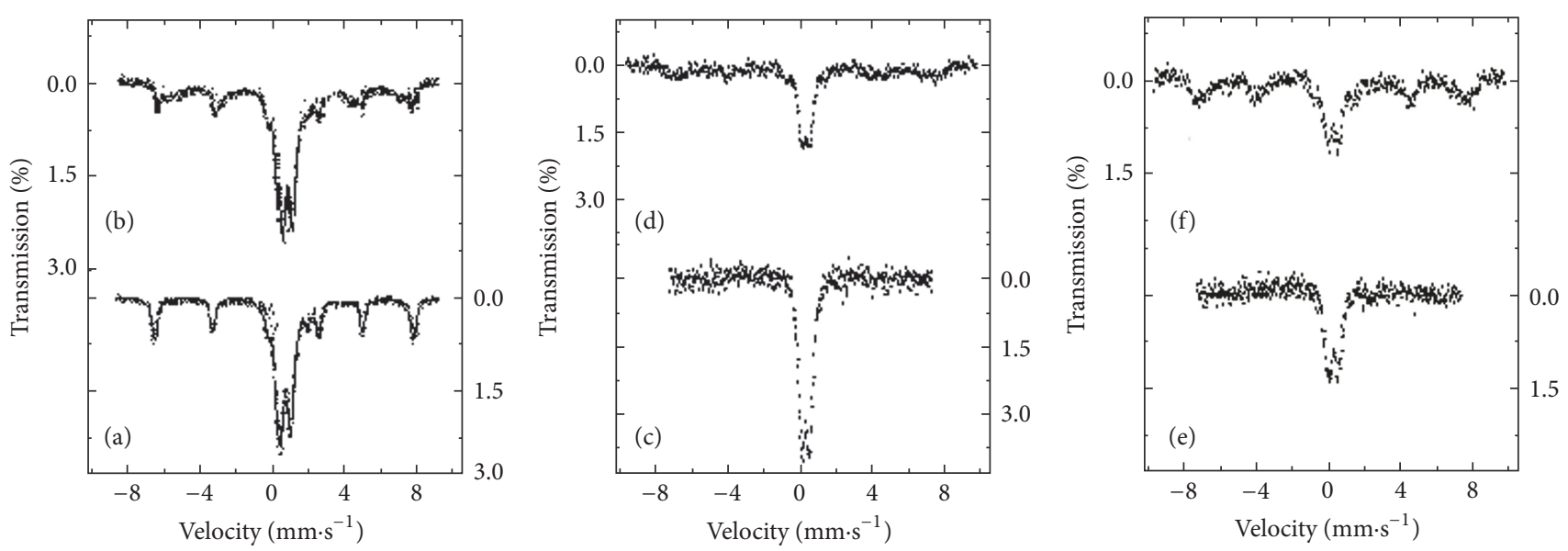

Figure 5: Mössbauer spectra for the pure saponite (a), palygorskite (c), and spondyle clay (e) and magnetic composites MCSp-7 (b), MCP-7 (d), and MCSd-7 (f).

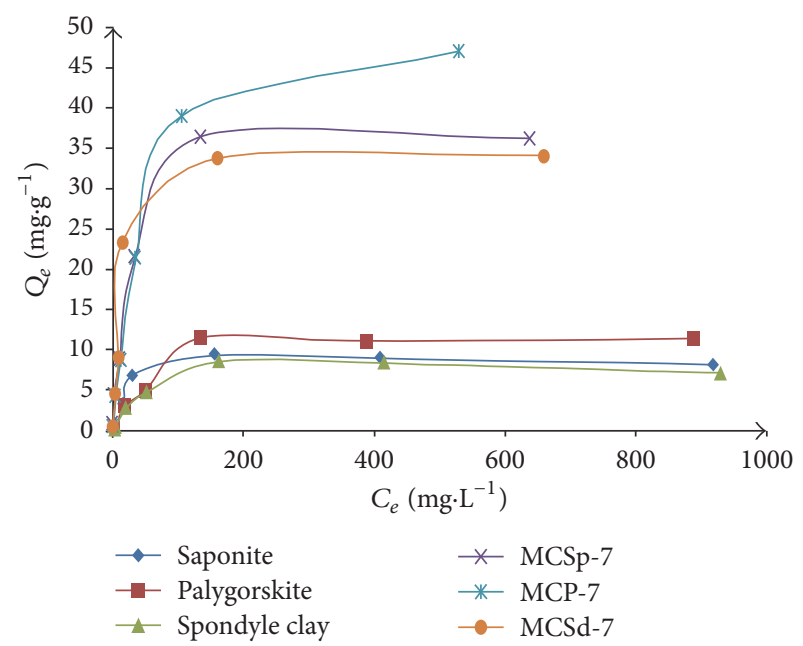

(a)

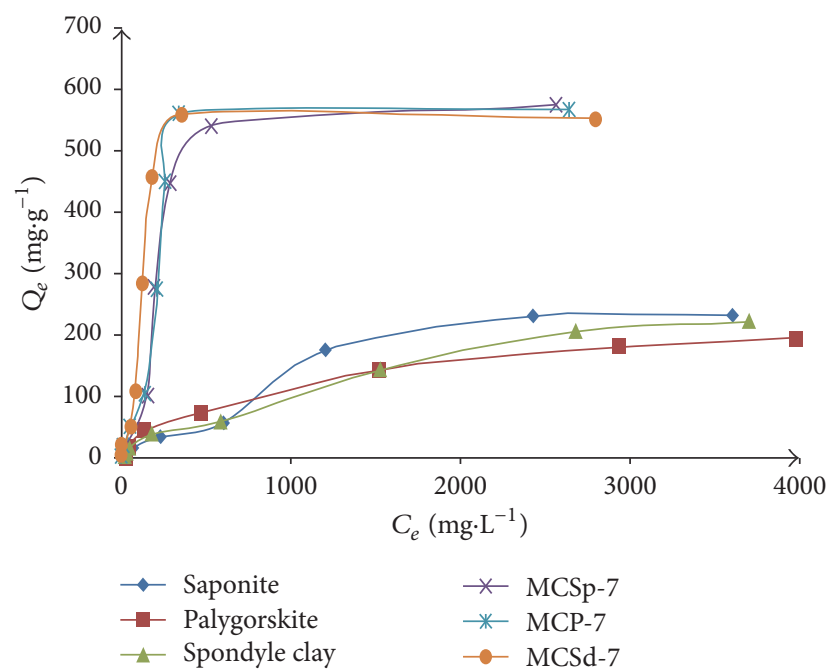

(c)

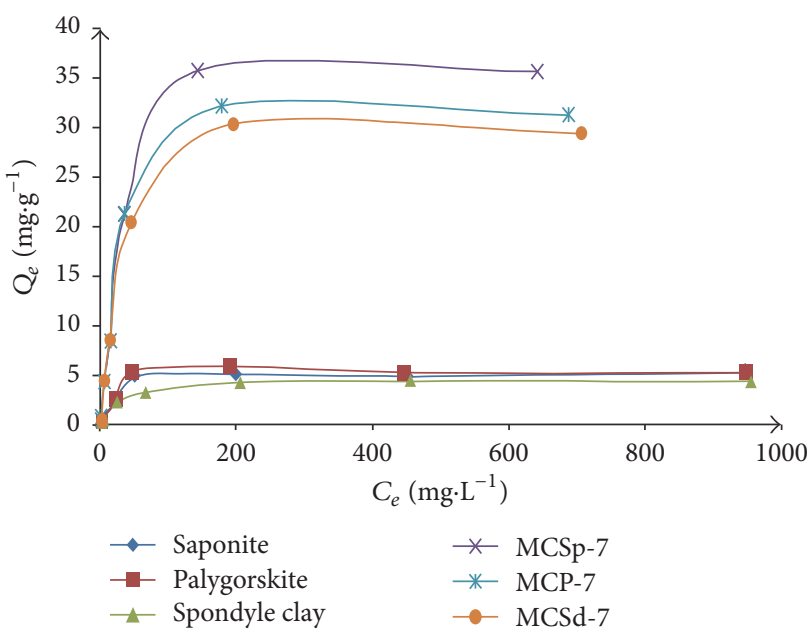

(b)

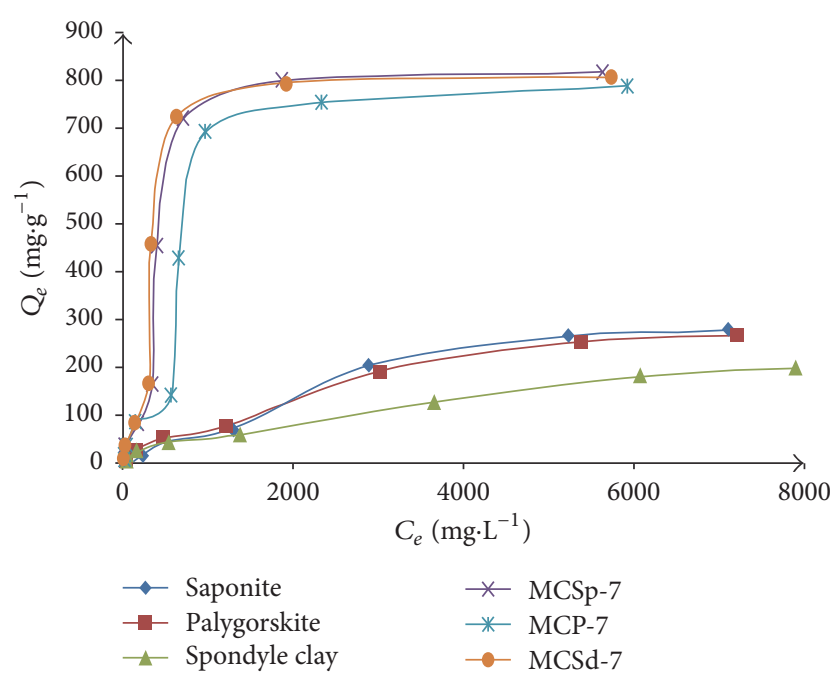

(d)

Figure 6: Adsorption isotherm of SDBS (a), SLS (b), TPP (c), and HMP (d) on sorbents samples. 
TABLE 3: Characteristics of the magnetic separation process of spent sorbents.

\begin{tabular}{|c|c|c|c|c|c|c|}
\hline \multirow{3}{*}{ Sample } & \multicolumn{3}{|c|}{$66 \mathrm{mT}$} & \multicolumn{3}{|c|}{$0 \mathrm{mT}$} \\
\hline & \multicolumn{6}{|c|}{$C, \mathrm{mg} / \mathrm{dm}^{3}$} \\
\hline & $5 \mathrm{~min}$ & $30 \mathrm{~min}$ & $60 \mathrm{~min}$ & $5 \mathrm{~min}$ & $30 \mathrm{~min}$ & $60 \mathrm{~min}$ \\
\hline Saponite & 558.8 & 387.7 & 327.1 & 555.7 & 384.2 & 326.0 \\
\hline MCSp-7 & 32.7 & 1.0 & $<0.5$ & 501.0 & 236.6 & 150.4 \\
\hline Palygorskite & 662.7 & 418.2 & 351.6 & 664.8 & 421.3 & 355.3 \\
\hline MCP-7 & 26.6 & $<0.5$ & $<0.5$ & 506.6 & 245.4 & 148.2 \\
\hline Spondyle clay & 713.8 & 526.0 & 464.9 & 712.4 & 523.7 & 466.5 \\
\hline MCSd-7 & 14.9 & 5.4 & $<0.5$ & 491.0 & 249.9 & 179.3 \\
\hline
\end{tabular}

change of porous structure of natural clay minerals caused by the formation of micropores and mesopores sorbent structure and stabilization of $\mathrm{Fe}_{3} \mathrm{O}_{4}$ nanoparticles on their pores surface. The comparative analysis of porous structures saponite clays and magnetic composites based on it are given in the work [13].

3.5. Magnetic Separation Process. Table 3 shows the kinetic of separation of clay minerals and magnetic composites in external magnetic field $66 \mathrm{mT}$ and in absence of permanent external magnetic field. Separation of magnetic sorbents from the purified solution in a filter equipped with permanent magnets was held 36 times faster. 98\% of spent magnetic sorbent mass was precipitated for the first 5 minutes by magnetic separation. Application of magnetic composites has ensured the achievement of the residual concentration of suspended solids $\leq 0.02 \mathrm{mg} / \mathrm{L}$ for 30 minutes of magnetic separation.

The residual concentration of magnetic composites was 2.5 times less than native clay sorbents at the separation in the absence of a magnetic field $(0 \mathrm{mT})$. Therefore, magnetic composites are ferromagnetic materials for which macroscopic magnetic moment, which exists even without external magnetic field, is available. As follows, efficiency of application of magnetic composites and implementing of magnetic separation in adsorption purification is obvious.

\section{Conclusions}

Magnetic nanocomposite sorbents on mineral base (saponite, palygorskite, and spondyle clay) were synthesized by impregnation method. The pure magnetic modifying agent $\mathrm{Fe}_{3} \mathrm{O}_{4}$ was obtained by method of Elmore.

The magnetic properties of nanosized magnetite stabilized by mineral matrix are primarily determined by the size of its particles. In the synthesis of MCSp-7, MCP-7, and MCSd-7 in the clay matrix the magnetite crystallites were formed approximately in the same range $(2-10 \mathrm{~nm})$. Magnetite particles in magnetic composites were in singledomain state and characterized by specific superparamagnetic properties. MC were classified to the soft magnetic materials.

The sorption capacities of obtained magnetic composites towards anionic surfactants and polyphosphates exceeded the sorption capacity of clay minerals by $2-8$ times. The detected effect was caused by stabilization of magnetite nanoparticles on the surface of clay pores and by the formation of micropores and mesopores sorbent structure.

Spent magnetic sorbents were removed from purified water by magnetic separation 36 times faster compared to the native clays. Thus, the use of magnetic nanocomposites based on natural clays and magnetite for the removal of organic pollutants is technologically and economically advantageous solution in water purification.

\section{Conflicts of Interest}

The authors declare that there are no conflicts of interest regarding the publication of this paper.

\section{References}

[1] L. Harutyunyan and G. Pirumyan, "Purification of waters from anionic and cationic surfactants by natural zeolites," Chemistry and Biology, vol. 1, pp. 21-28, 2015.

[2] O. Makarchuk and T. Dontsova, "Removal of polyphosphates from wastewater by magnetic composite mineral sorbents," European Chemical Bulletin, vol. 5, no. 12, pp. 515-523, 2016.

[3] R. Priti and D. Hemangi, "Removal of anionic surfactant sodium dodecyl sulphate (SDS) from aqueous solution by using alumina," J. Environ. Res. Develop, vol. 7, pp. 851-862, 2012.

[4] O. Vladimirovna Makarchuk and T. Anatolievna Dontsova, "Removal of anionic surfactants from wastewater by magnetic mineral sorbents," Journal of Water Security, vol. 2, no. 1, 2016.

[5] T. Osalo, E. Merufinia, and M. Saatlo, "Phosphorus removal from aqueous solutions by bentonite: effect of $\mathrm{Al}_{2} \mathrm{O}_{3}$," Journal of Civil Engineering and Urbanism, vol. 3, no. 5, pp. 317-322, 2013.

[6] A. Bhatnagar and M. Sillanpää, "Utilization of agro-industrial and municipal waste materials as potential adsorbents for water treatment-a review," Chemical Engineering Journal, vol. 157, no. 2-3, pp. 277-296, 2010.

[7] D. Kaušpediene, E. Kazlauskiene, A. Gefeniene, and R. Binkiene, "Comparison of the efficiency of activated carbon and neutral polymeric adsorbent in removal of chromium complex dye from aqueous solutions," Journal of Hazardous Materials, vol. 179, no. 1-3, pp. 933-939, 2010.

[8] M. J. Sánchez-Martín, M. C. Dorado, C. del Hoyo, and M. $\mathrm{S}$. Rodríguez-Cruz, "Influence of clay mineral structure and surfactant nature on the adsorption capacity of surfactants by clays," Journal of Hazardous Materials, vol. 150, no. 1, pp. 115123, 2008. 
[9] Y. Gao, N. Chen, W. Hu et al., "Phosphate removal from aqueous solution by an effective clay composite material," Journal of Solution Chemistry, vol. 42, no. 4, pp. 691-704, 2013.

[10] N. Mykhailenko, O. Makarchuk, T. Dontsova, S. Gorobets, and I. Astrelin, "Purification of aqeous media by magnetically operated saponite sorbents," Eastern European Journal of Enterprise Technologies, vol. 4, no. 10, pp. 13-20, 2015.

[11] O. V. Makarchuk, T. A. Dontsova, and I. M. Astrelin, "Magnetic clay sorbent for the removal of dyes from aqueous solutions," Research Bulletin of the National Technical University of Ukraine "Kyiv Polytechnic Institute", vol. 6, pp. 109-114, 2015.

[12] C. V. Thach, N. H. Hai, and N. Chau, "Size controlled magnetite nanoparticles and their drug loading ability," Journal of the Korean Physical Society, vol. 52, no. 5, pp. 1332-1335, 2008.

[13] O. V. Makarchuk, T. A. Dontsova, and I. M. Astrelin, "Magnetic nanocomposites as efficient sorption materials for removing dyes from aqueous solutions," Nanoscale Research Letters, vol. 11, article 161, 2016.

[14] T. M. Schmitt, Anaysis of Surfactants, Marcel Dekker, New York, NY, USA, 2001.

[15] H. Waldhoff and R. Spilker, Handbook of Detergents. Part C: Analysis, CRC Press, Taylor \& Francis Group, Boca Raton, Fla, USA, 2004.

[16] R. D. Kos'yan, I. S. Podymov, and S. Y. Kuznetsov, “Turbidimetric measuring of the suspended sediment concentration in the coastal zone," in Proceedings of the 1998 26th International Conference on Coastal Engineering, ICCE-98, vol. 26, pp. 23032316, 1998.

[17] G. F. Goya, T. S. Berquó, F. C. Fonseca, and M. P. Morales, "Static and dynamic magnetic properties of spherical magnetite nanoparticles," Journal of Applied Physics, vol. 94, no. 5, pp. 3520-3528, 2003.

[18] A. Doroshenko and I. Chekman, "Magnetic nanoparticles: properties and biomedical applications," Ukrainian Medical Journal, vol. 4, no. 102, pp. 10-13, 2014. 

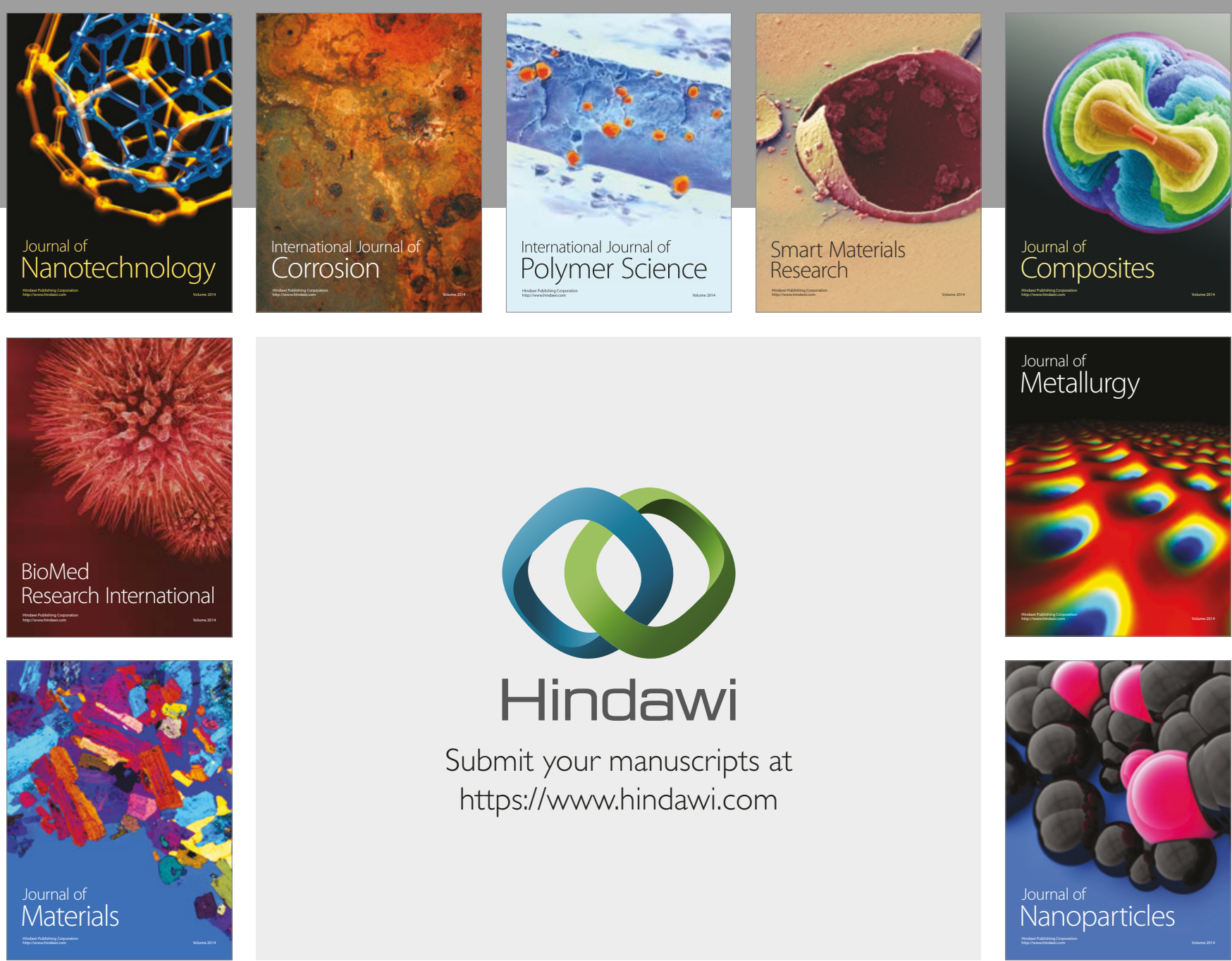

\section{Hindawi}

Submit your manuscripts at

https://www.hindawi.com
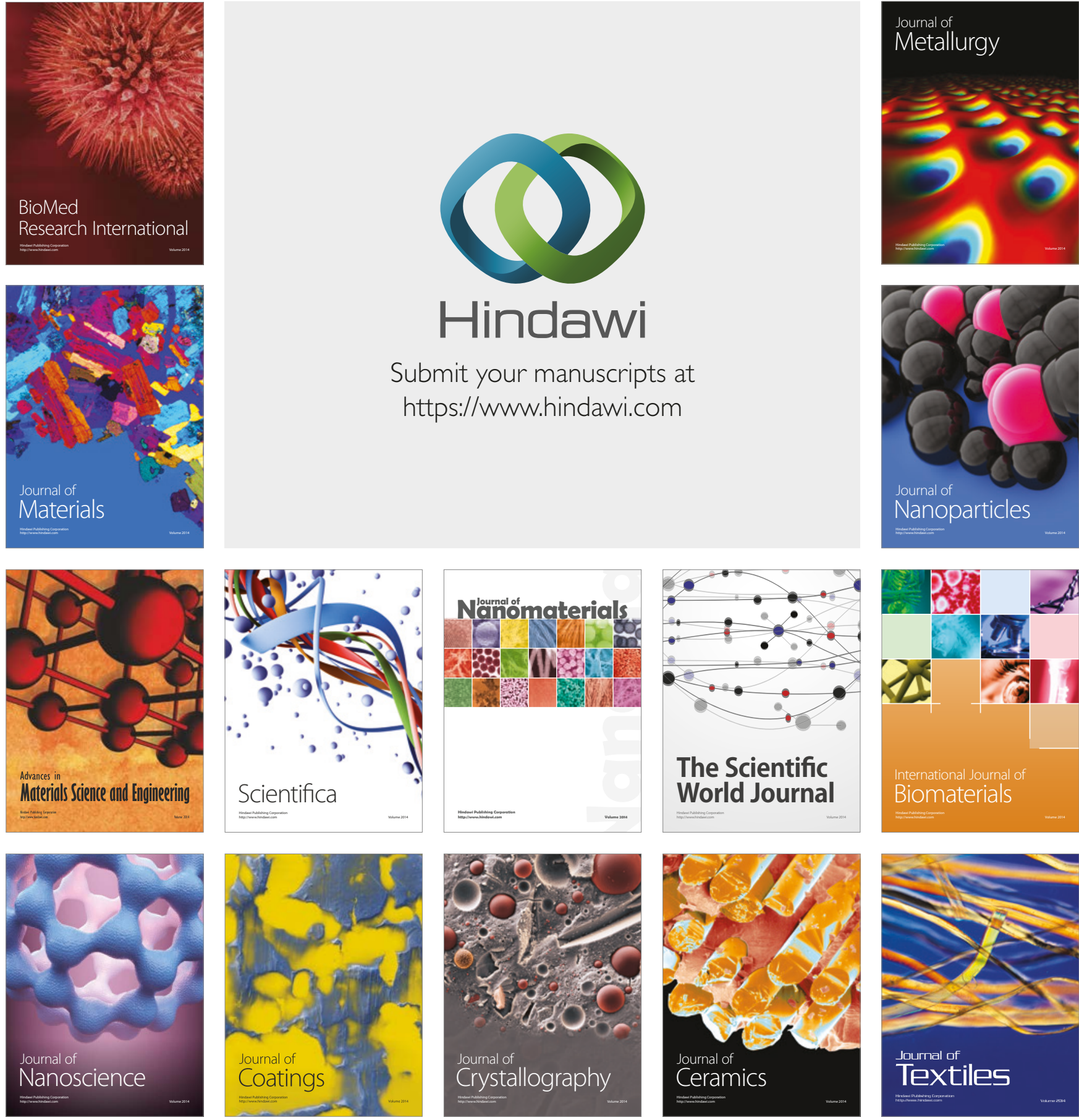

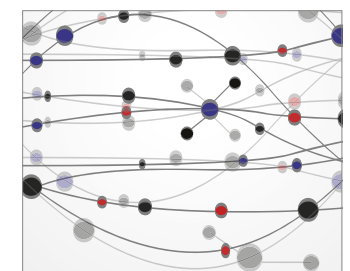

The Scientific World Journal
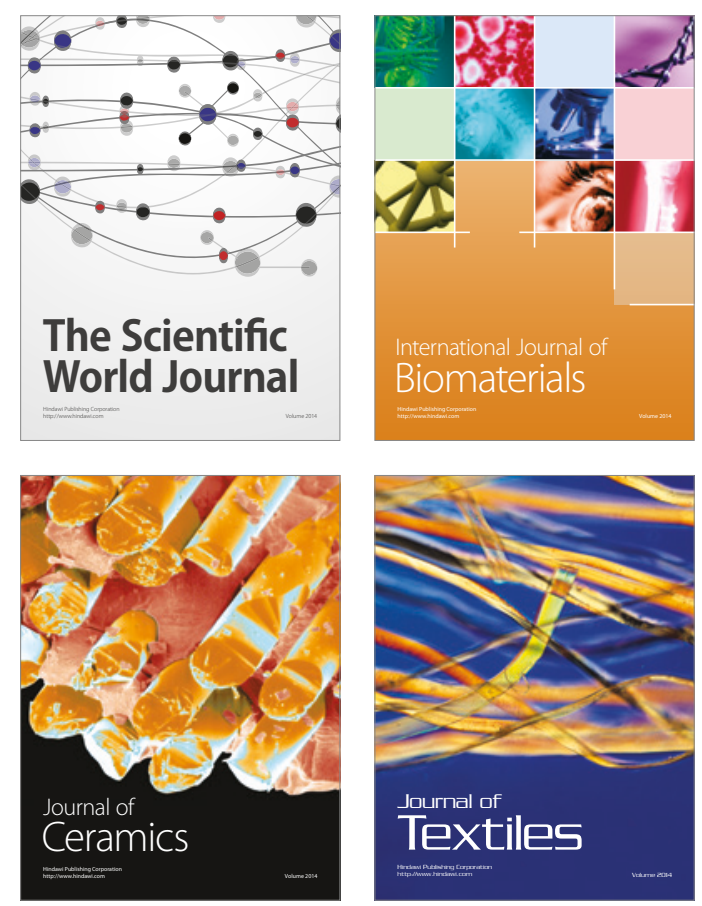